\title{
Impact of the grooves on the enhancement of heat transfer in an annular space of a rotor-stator
}

\author{
Attou Youcef*, Dellil A. Zineddine, Meghdir Abed \\ Department ELM, Institute of Maintenance and Industrial Safety, University of Mohamed Ben Ahmed Oran 2, Algeria
}

Corresponding Author Email: attouyoucef27@gmail.com

https://doi.org/10.18280/ijht.360417

Received: 16 August 2017

Accepted: 6 March 2018

\section{Keywords:}

grooves, shear stress transport model, turbulence, heat transfer, ANSYS fluent code

\begin{abstract}
This work concerns a numerical study of heat transfer by convection in an annulocylindrical space of an axial air flow between a rotor rotating at constant angular velocity and a fixed stator. We used the Fluent software to simulate the thermal influence on the groove. We propose to study four geometric configurations of the rotor and stator. The first is to take the surfaces of the rotor and the stator as smooth. In the second configuration, the stator wall is grooved along the cylinder and the rotor is smooth. For the third, it is considered that the rotor and the stator are provided with grooves of the same geometrical shape as regards the last case; it is only on the rotor that the same types of grooves are considered. The numerical results obtained in rotational flow for different rotational speeds of the rotor and for different air injection rates through grooves of different depth values have shown that the presence of grooves enhances the heat transfer at as speed increases. In the presence of an axial flow of air, the results obtained in a turbulent flow show that the case of the grooved rotor is interesting from the thermal point of view with respect to the others (smooth, grooved stator, and grooved rotor-stator). This numerical study is based on the use of an SST (Shear-Stress-Transport) type turbulence model to evaluate heat exchanges in the various rotor-stator configurations.
\end{abstract}

\section{INTRODUCTION}

The design of electro technical or electronic components is increasingly miniaturized and highly reliable but is limited by considerations such as heat dissipation problems. These components are temperature sensitive because their performance decreases as the temperature increases and can even be destroyed under its effect. The study of the phenomena of heat transfer in electrical machines has been the subject of much research work. In these machines there is a combination of several physical processes of electrical, mechanical and magnetic origin. The amount of heat generated by these irreversible phenomena results in high temperature levels in certain parts of these machines (insulators, bearings). The evacuation of this quantity of heat requiring bulky accessories is not always easy, especially in the field of aviation, where the improvement of the mass power passes through the optimization of the cooling circuits of the engine. Dissipations originate mainly in the electrical conductors and in the active magnetic mass of the rotor and the stator. These two subassemblies of the electrical machine constitute an annular space called air gap, in which a cooling fluid circulates. According to the technology used, the fluid generally used, namely air, passes between the rotating rotor and the stationary stator. Our study therefore focuses on the means of improving this heat transfer, since the energy dissipated in the heating resistor of a rotor-stator is not dissipated in its entirety by the air flow. A certain quantity is lost by radiation from this wall towards the fluid and consequently towards the outer wall of the rotor. The aim of this study is to show the impact of the rotational speed of the rotor, the axial velocity of the air and especially the presence of grooves on the rotor or the stator on the heat transfer. Studies carried out in this field have shown that there could be four flows in this annular space consisting of a rotor moving in a body called a stationary stator:

Laminar flow

Laminar flow with secondary flow (composed of Taylor vortices).

Turbulent flow

Turbulent flow with Taylor vortices [1]. Any thermal study of electrical machines is aimed at evaluating the temperature distribution in order to improve materials, geometry, or cooling system and to avoid operating regimes that damage the machine and reduce its duration of life. Three situations can be distinguished in the literature. The first concerns a smooth air gap with no axial flow. Much research has been carried out, among which, Gazley [2] studied theoretically and experimentally the convective exchanges for an air gap of $254 \mathrm{~mm}$ in length with a width $\mathrm{e}=0.445 \mathrm{~mm}$ and $\mathrm{e}=6.095 \mathrm{~mm}$ by varying the rotational speed between 0 and $4700 \mathrm{rpm}$. Becker and Kaye [3] experimentally studied the case of a single air gap of $8,115 \mathrm{~mm}$ in width and a length of $1,42 \mathrm{~m}$, a shape ratio e / $\mathrm{Rr}=0,235$. Aoki et al. [4] experimentally studied the heat transfer in a smooth air gap without axial flow for different fluids (air, water, alcohol and oil) whose Prandtl numbers are respectively $0.71 ; 4.5 ; 45$ and 160 . Different combinations of speed and gap size were tested. Five gap widths were available $\mathrm{e}=2.08 ; 2.71 ; 3.54 ; 3.70$ and $4.67 \mathrm{~mm}$. Tachibana et al. [5] have studied the heat transfer in a gap of a rotor and a stator, for different thickness $4 \mathrm{~mm}, 8 \mathrm{~mm}, 11 \mathrm{~mm}, 12 \mathrm{~mm}$, $20 \mathrm{~mm}, 53 \mathrm{~mm}$ and $21.35 \mathrm{~mm}$; The fluids that have been used are: air, water and methanol. More recently, Ball et al. [6] 
were interested in heat flux that are related to the velocity field of the structure in the rotating systems with air as the cooling fluid. They carried out two studies, the first was to study the flow through the annular space and the second was a qualitative study by visualization using smoke for the secondary flows, the authors noted that the heat transfer increases when the thickness of the air gap is smaller. [2, 4], Lee and Minkowyck [7] have also studied the influence of axial flow and heat transfer in a gap for a combined flow. Julien Pellé et al. [8] made an experimental study to determine the convective exchanges in the gap in the presence of a jet of air, and for that they used a rotor radius $\mathrm{R}$ $=310 \mathrm{~mm}$ and a stator with the same radius having a central opening of diameter $\mathrm{D}=26 \mathrm{~mm}$ where the thickness of the air gap is $3<\mathrm{e}<50 \mathrm{~mm}$.An opening placed in the center of the stator allowed Julien Pellé et al. [8] and Julien Pellé and Souad Harmand [9] to experimentally show the improvement of heat transfer even locally and numerically by Andersson and Lygren [10] using large eddy simulation model "LES", Haddadi et al. [11] using RANS modeling. The presence of grooves at the air gap can be an important parameter for air flow or heat transfers. The configuration of a grooved gap has been relatively little studied in the literature. One of the first studies dealing with grooved gaps was conducted by Gazley [12]. The latter used various geometries under the same study conditions as for the smooth air gaps. Gardiner et al. [13] studied the convective heat transfer coefficient in a grooved gap and another in a smooth one. They evaluated the influence of grooves and compared their experimental results with a smooth gap aspect ratio of $\mathrm{e} / \mathrm{Rr}=0.107$ ) to those obtained with a grooved gap at the rotor level. The grooves are 30 in number and have the following dimensions: depth of $1.6 \mathrm{~mm}$ and width of $3.2 \mathrm{~mm}$. There are other works in the literature that characterized the convective transfer of grooved gap. Bouafia et al. [14] have developed an experimental model allowing access to the axial development of the rotor surface temperature. They evaluated the convective transfer in the air gap once for a rotor with an outside diameter of $\mathrm{De}=280 \mathrm{~mm}$ and the stator with internal diameter $\mathrm{Di}=293 \mathrm{~mm}$ and a second geometry with a smooth rotor and a grooved stator (48 grooves with a depth of $15 \mathrm{~mm}$ and a width of $8.3 \mathrm{~mm}$ ), with or without axial flow. Peres et al. [15] studied numerically the convective exchanges in the same groove gap to the stator as Bouafia et al. [14] and they noticed that the air enters the grooves in the case of a combined flow, further; recirculations are created in the grooves. Bouafia et al. [16] continued their work by combining experimental and numerical study. The authors were able to show again the interest of grooves to intensify the transfers. Fénot et al. [17] have reviewed the different articles concerning the improvement of heat transfer between concentric rotating cylinders in with or without axial flow.

More recently, the studies presented in the literature are oriented towards rotor channels of rectangular cross-sectional shape. Neti et al. [18] have developed a digital code based on finite differences. This code allows the study of heat transfers in rectangular shaped channels. Levy et al. [19] compared the numerical results with experimental results. Two rectangular channels were studied: the first $\left(\mathrm{d}_{\mathrm{h}}=3.18 \mathrm{~mm}\right)$ is for pressure measurements, the second $\left(\mathrm{d}_{\mathrm{h}}=10.5 \mathrm{~mm}\right)$ for the heat transfer analysis. Both are used in a laminar flow. More recently, Soong and Yan [20] numerically studied the development of secondary flows due to the rotation and the heat transfer for rectangular channels. Micallef et al. [21] studied the consequences of a change in the geometry of involutes. They have thus been able to demonstrate the effects linked to the change of profiles (more or less angular walls) and the inclination of the involutes. Tzer-Ming Jeng et al. [22] have studied experimentally the heat transfer characteristics of the flow Taylor-Couette-Poiseuille in an annular channel with ribs which rise longitudinally on the rotating inner cylinder. Axial ranges of Reynolds number $\left(\mathrm{R}_{\mathrm{e}}\right.$ axial) and the Rotational Reynolds number $\left(\mathrm{R}_{\mathrm{e} \Omega}\right)$ are $\mathrm{R}_{\mathrm{e} \text { axial }}=$ 30-1200 and $R_{\mathrm{e} \Omega}=0-2922$. Three modes of the inner cylinder with and without longitudinal ribs are considered. Recently, Pietro Romanazzi and David A. Howey [23] studied the heat transfer in the air gap (in smooth narrow gaps and slotted rotor) of an SRM with the unsteady LES solver using the commercial CFD code STAR-CCM+. More recently the heat transfer in an annulus between coaxial cylinders with slots had been studied [24-26]. Fénot et al. [27] were interested in convective exchanges in the gap in the case where only the rotor is grooved (4 slots). They did their studies on an open synchronous motor with 4 poles; the authors studied the influence of the air flow on the convective transfer and they noticed thus, that it is dependent on the speed of axial rotation and that of the rotor. Nicolas Lancial et al. [28] have shown the effect of the flow of Taylor-Couette-Poiseuille in an annular channel of a rotating slotted inner cylinder and to improve the arrangement of the flow and the thermal phenomena in electric machines that utilize a simplified scale model. Their results prove that the Nusselt number is proportional to the Reynolds number tangential to the $1 / 7$ power in the pole and the inductive drag side of the face.

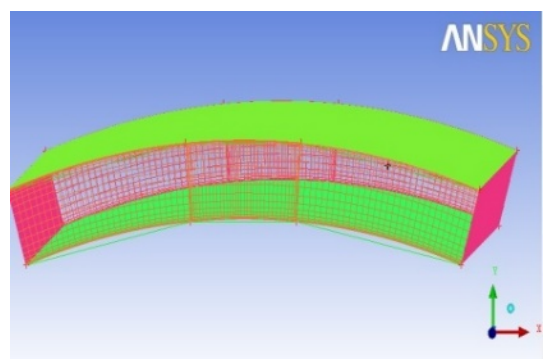

Figure 1. Smooth conduit

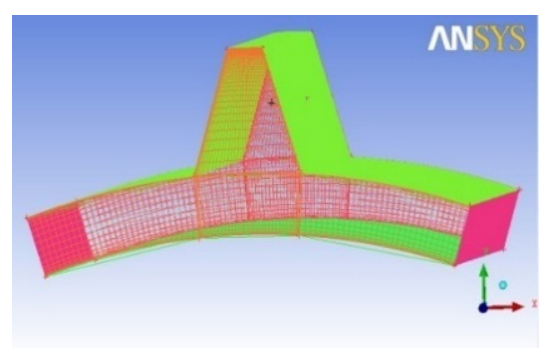

Figure 2. Grooved stator

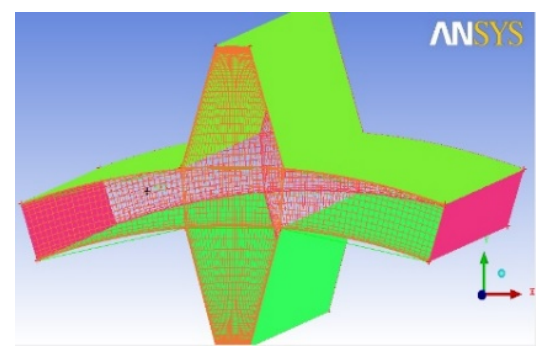

Figure 3. Grooved stator and rotor 


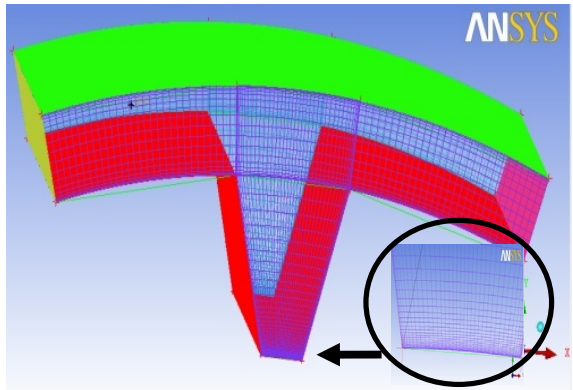

Figure 4. Grooved rotor

The effect of the change of the geometry by the presence of grooves on the stator, the rotor and the stator at the same time or on the rotor only, as a function of the variation of the rotor rotation speed, the axial velocity of cooling air and the variation of the value of the air gap will be the essence of our study. The four configurations cited below are represented by figures. 1, 2, 3 and 4.

In finless driving, we tested several air gaps to evaluate the impact of this space on heat transfer. The heat transfer in this space known as the air gap is influenced by the rotor rotation speed, the air blowing speed, the temperature gradient between the stator and the rotor and the roughness of the surfaces. G.I. Taylor [1], analyzing the stability of this viscous flow in this air gap introduced the Taylor number which characterizes this type of flow:

$T_{a}=\frac{w^{2} R_{1}\left(d_{h} / 2\right)^{3}}{v^{2}}$

If this number is less than a critical value, the flow is laminar, otherwise there will be contra-rotating eddies if this critical value is exceeded. First, we studied the flow of air in the air gap for different rotational speed of the rotor and for different axial velocities of the air. Secondly, in the presence of trapezoidal grooves on the rotor or on the stator and with the same variables; we have modeled the convective exchanges in this space. The rotational speed can reach 6000 rev / min for the rotor which corresponds to a value of the Taylor number of $4.810^{4}$. In the presence of axial flow, turbulent flow is characterized by Reynolds numbers up to $3.110^{4}$ values in clean configuration and $1.710^{4}$ in grooved configuration. The numerical study is carried out in annulocylindrical geometry with a grooved rotor. The model used is the model SST (Shear Stress Transport). For this finned geometry, the Taylor number is modified by introducing a shape factor considering the shape of the groove.

$$
\begin{aligned}
& T_{a m}=\frac{\omega^{2} r_{m} e^{3}}{v^{2}}\left(\frac{1}{F}\right) \\
& r_{m}=\frac{e}{\ln R_{2} / R_{1}} \\
& F=\frac{\pi^{4}}{1697}\left[1-\frac{e}{2 r_{m}}\right]^{-2} P^{-1} \\
& P=0.0571\left[1-0652\left(\frac{e / r_{m}}{1-e / r_{m}}\right)\right]+0.00056\left[1-0.652\left(\frac{e / r_{m}}{1-e / r_{m}}\right)\right]^{-1}
\end{aligned}
$$

F: Geometric Factor steaming from Taylor's work. $\omega$ : Represents the rotational speed. e: Thickness of the air-gap (groove + rotor)

$N u=0.064 T_{a m}^{0.367}$

For the axial and tangential velocities, the different Reynolds numbers are introduced:

$R_{\text {eaxial }}=V d_{h} / v$

$R_{\text {etan gential }}=w R_{1} d_{h} / v$

$R_{e}=\sqrt{R_{\text {eaxial }}+R_{\text {etan gential }}}$

Based on the Nicolas Lancial et al. [28] findings, the present work aims to study the effect of the variation of the depth of the groove for different rotational speeds and air injection to enhance the rate of heat transfer.

\section{NUMERICAL MODEL}

The numerical simulation was carried out by the Fluent 14.0 code. For cooling the electric machine, we used the Model SST (Shear- stress- transport) [29]. Under an unfavorable pressure gradient, the detachment plays an important role near the wall (intensification of heat transfer). The SST model has demonstrated the potential for accurate predictions of separation in many cases. The idea behind the SST is to combine the model $k-\varepsilon$ and model $k-\omega$ using damping coefficients $f_{1}$. The latter is equal to 1 near the wall and zero away from the wall. It activates the model of Wilcox $(k-\omega)$ in the region near the wall and model $k-\varepsilon$ for the rest of the flow. By this approach, the execution of the Wilcox model [30], can be used without potential errors. The formulation of the SST model is as follows:

$$
\begin{aligned}
& \frac{\partial(\rho k)}{\partial t}+\frac{\partial\left(\rho U_{j} k\right)}{\partial x_{j}}=\widetilde{P}_{k}-\beta^{*} \rho k \omega+\frac{\partial}{\partial x_{j}}\left(\Gamma_{k} \frac{\partial k}{\partial x_{j}}\right) \\
& \frac{\partial(\rho \omega)}{\partial t}+\frac{\partial\left(\rho U_{j} \omega\right)}{\partial x_{j}}=\frac{\gamma}{v_{t}} P_{k}-\beta \rho \omega^{2}+\frac{\partial}{\partial x_{j}}\left(\Gamma_{\omega} \frac{\partial \omega}{\partial x_{j}}\right) \\
& +2 \rho \sigma_{\omega 2} \frac{1}{\omega} \frac{\partial k}{\partial x_{j}} \frac{\partial \omega}{\partial x_{j}}
\end{aligned}
$$

With:

$P_{k}$ represents production of turbulent kinetic energy due to the gradient of the average velocity:

$$
\begin{aligned}
& \Gamma_{k}=\mu+\frac{\mu_{t}}{\sigma_{k}} ; \Gamma_{\omega}=\mu+\frac{\mu_{t}}{\sigma_{\omega}} ; P_{k}=\tau_{i j} \frac{\partial U_{i}}{\partial x_{j}} ; \\
& \widetilde{P}_{k}=\min \left(P_{k}, C_{1 \varepsilon}\right) \\
& \overline{u_{i} u_{j}}=\frac{2}{3} k \delta_{i j}-v_{t} S_{i j}
\end{aligned}
$$

where $v_{t}$ is turbulent kinematic viscosity computed by combining $k$ and $\varepsilon$ : 
$v_{t}=c_{\mu} f_{\mu} \frac{k^{2}}{\varepsilon}$

With the mean strain rate tensor, $S_{i j}$, defined as

$S_{i j}=\left(\frac{\partial U_{i}}{\partial x_{j}}+\frac{\partial U_{j}}{\partial x_{i}}\right)$

The coefficients $\varphi_{1}$ and $\varphi_{2}$ of the model are functions of:

$\varphi=f_{1} \varphi_{1}+\left(1-f_{1}\right) \varphi_{2}$

The skin friction coefficient, $C_{f}$ is defined by:

$C_{f}=\frac{1}{2} \frac{\tau_{P}}{\rho U_{\tau}^{2}}$

The friction velocity $U_{\tau}$ can be defined in the following way:

$U_{\tau}=\sqrt{\tau_{P} / \rho}$

where $\tau_{P}$ is the wall shear stress.

Where the coefficients of the model $k-\omega$ and $k-\varepsilon$ the model are respectively equal to:

$\sigma_{k_{1}}=2.0 ; \sigma_{\omega_{1}}=2.0 ; \kappa=0.41 ; \gamma_{1}=0.5532 ; \beta_{1}=0.075$;

$\beta^{*}=0.09 ; C_{1}=10$;

$\sigma_{k_{2}}=2.0 ; \sigma_{\omega_{2}}=1.168 ; \gamma_{2}=0.4403 ; \beta_{2}=0.0828$;

$\beta^{*}=0.09$

\subsection{Presentation of the FLUENT 14.0 code}

The present simulations were performed using the Fluent 14.0 software from ANSYS, Inc. The Fluent code uses the finite volume method for discretization of the continuity, momentum, and energy equations. In this method, we integrate the conservation equations applied to each elementary control volume. From the variables known at the centers of volumes, the fluxes are evaluated at the surfaces of the volumes by interpolation. This method gives very good results because it guarantees the conservation of the mass and thermal balances over the whole area studied. Originally developed by Patankar and Spalding [31], this method applied to the resolution of Navier-Stokes equations, developed during the $1980 \mathrm{~s}$. It is a method based on the integral formulation of the equations on each of the faces of the joining volumes, called the control volume, surrounding each evaluation node. The finite volume method can be summarized as follows:

Discretize the physical domain into a set of control volumes

Carry out mass and quantity balances on these volumes

The equations of Navier Stocks considered for incompressible fluid are:

A. Equation of continuity

$\frac{\partial u_{j}}{\partial x_{j}}=0$
B. Equation of movement quantity

$\rho U_{j} \frac{\partial}{\partial x_{j}}\left(U_{i}\right)=-\frac{\partial P}{\partial x_{j}}+\mu \frac{\partial^{2} u_{i}}{\partial x^{2}}+\underbrace{\frac{\partial}{\partial x_{j}}\left(-\rho \overline{u_{i}^{\prime} u_{j}^{\prime}}\right)}_{\text {Constraints of Reynolds }}+\rho g_{i}$

C. Equation of Energy

$\frac{\partial}{\partial x_{j}}\left(\rho U_{j} T\right)=\frac{\lambda}{C p} \frac{\partial^{2} T}{\partial x^{2}{ }_{j}}+\frac{\partial}{\partial x_{j}}\left(-\overline{\rho u_{j}^{\prime} t_{p}^{\prime}}\right)$

All these equations can be written in the following general form:

$\underbrace{\frac{\partial\left(\rho u_{j} \phi\right)}{\partial x_{j}}}_{1}=\underbrace{\frac{\partial}{\partial x_{j}}\left(\Gamma_{\phi} \frac{\partial \phi}{\partial x}\right)}_{2}+\underbrace{S_{\phi}}_{3}$

Term 1: transport of $\phi$ by convection.

Term 2: transport of $\phi$ by diffusion.

Term 3: local production of $\phi$.

ICEM CFD Allows to prepare the geometrical configuration of the studied problem and to generate the mesh in a rather user-friendly way, although quite simple. One of the advantages of this software is its simplicity as well as its robustness towards the realization of the most complex geometries. For the mesh, ICEM CFD 14.0 uses mono or multi-block structures according to the geometry; it makes it possible to generate two types of meshes, among others the mesh tetrahedron and hexahedron.

\subsection{Optimization of the mesh}

With the same adopted mesh, namely 602420 nodes and to validate our case, we tested the first case (smooth), then the second case (grooved stator), the third case (grooved rotor) and finally the last case (grooved rotor -stator), and compared them on the same graph (figure 7). We adopted a refined mesh O-grid near the walls of the air gap space made up of the trapezoidal groove and the rest of the rotor.

Table 1. Tested grids

\begin{tabular}{lccc}
\hline & Type & Elements & Nodes \\
\hline Mesh1 & Hexahedral & 322728 & 302580 \\
Mesh2 & Hexahedral & 637716 & 602420 \\
Mesh3 & Hexahedral & 1273156 & 1204840 \\
\hline
\end{tabular}

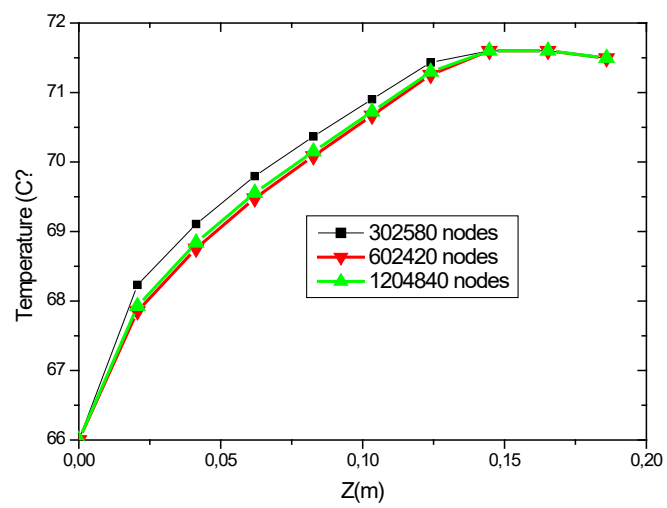

Figure 5. Mesh sensibility 


\subsection{Boundary conditions}

All equations developed to describe a turbulent flow are partial differential equations. To solve them, the boundary conditions must be defined.

In this case, the flow is tridimensional, turbulent, stationary and compressible.

At the entrance: $\mathrm{V}=\mathrm{Vin}$, with $\mathrm{V}$ in is from 1 to $10 \mathrm{~m} / \mathrm{s}$.

The turbulence intensity is equal to $10 \%$

Temperature of the incoming fluid, Tin $=300 \mathrm{~K}$

A constant temperature $\left(\mathrm{Tw}=71.6^{\circ} \mathrm{C}\right)$ was applied on the walls of the rotor.

The rotation speed of the rotor is ranging from 10 to 628 $\mathrm{rd} / \mathrm{s}$

The pressure gradient at the outlet is equal to 0 .

The periodicity has been processed to reduce the time and cost of calculation

The geometry is shown in the following figure whose dimensions are expressed in [mm].

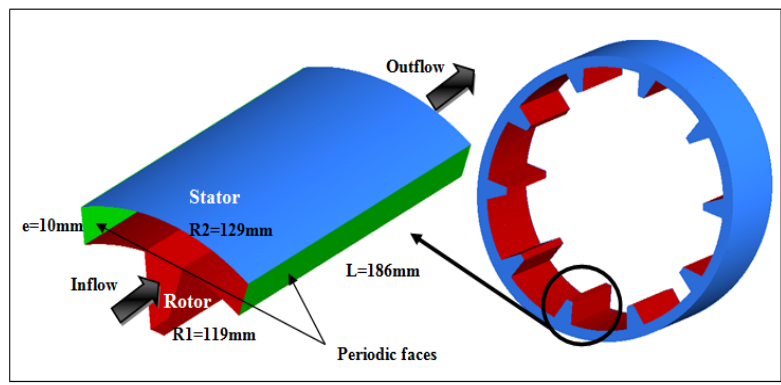

Figure 6. Grooved rotor geometrical configuration

\subsection{Validation of results}

Three meshes were tested (Table 1) and the second mesh (637716 elements) was chosen. The results obtained have been validated with the experimental work of N. Lancial et al. [28] (see Figure 7).

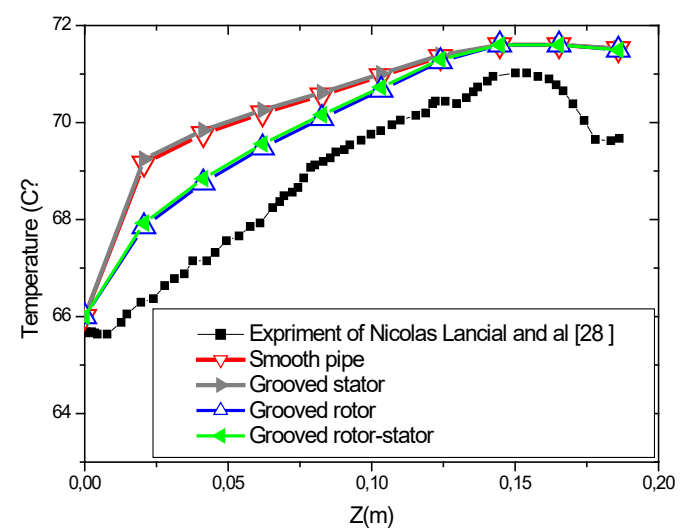

Figure 7. Evolution of the temperature

If one compares the temperature profile evolution for the four cases, namely the temperature profile of a smooth pipe, a grooved rotor, a grooved stator and a grooved rotor and stator, it is found that the temperature profile of the grooved rotor and the grooved rotor-stator is advantageous with respect to the other two configurations for rotational speeds. As a result, in all cases stemming from the 4 configurations, the grooved rotor exhibits better thermal performances.

\section{RESULTS AND DISCUSSIONS}

\subsection{Rotation speed impact}

Figure 8 shows the temperature distribution for the same trapezoidal grooves of the heated rotor. It can be seen in this figure that all the temperature profiles show a same profile along the rotor (for $\mathrm{Z}$ varying from 0 to $0.186 \mathrm{~m}$ ). The effect of the rotation speed is clearly visible from $10 \mathrm{rd} / \mathrm{s}$ to $157 \mathrm{rd} / \mathrm{s}$. The temperature increases with the speed of rotation. There is a gain of about $3^{\circ} \mathrm{C}$, which is not negligible. The temperature difference increases when the rotor rotates at high speed for a depth of the groove $\mathrm{p}=20 \mathrm{~mm}$.

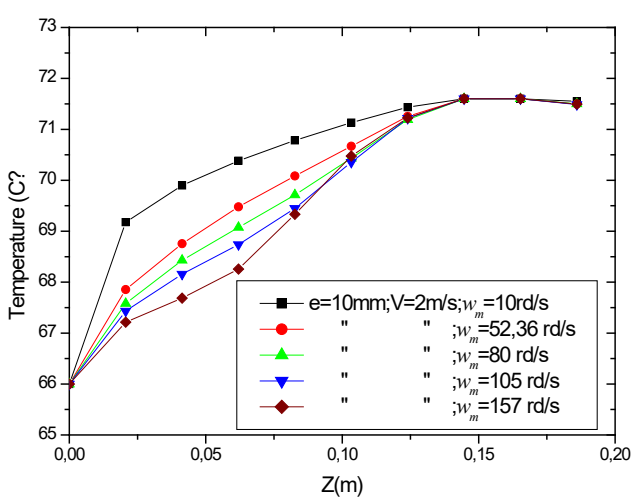

Figure 8. Temperature evolution following axis $\mathrm{Z}$

Fig. 9 shows the increase in the number of Nusselt from the value 100 to about $\mathrm{Nu}_{\max }=200$, which give good heat transfer, but in parallel Fig. 10 also shows an increase in the coefficient of friction with the rotational speed of the rotor to a maximum value of about $\mathrm{Cf}_{\max }=1.2$.

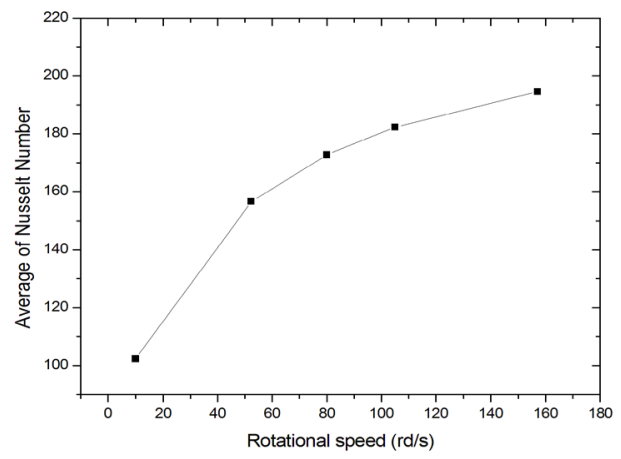

Figure 9. Average Nusselt number variation

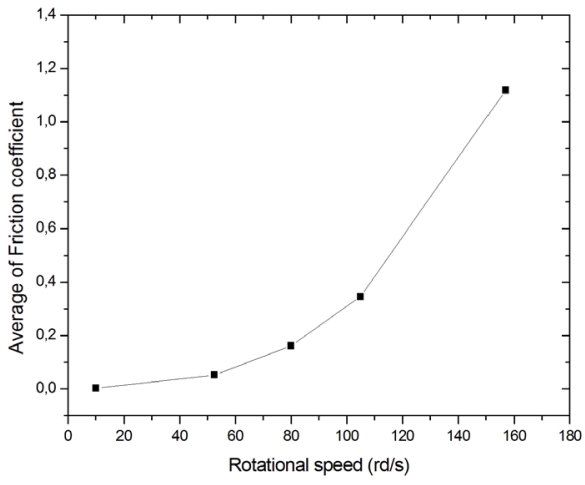

Figure 10. Average friction coefficient variation 


\subsection{Impact of injection speed}

In Fig. 11, the profile of the temperature is plotted for different air injection speeds and the change in temperature for the finned rotor is noted. It is also observed that the groove is cooled when the air is injected at high speed at $\mathrm{V}=$ $7 \mathrm{~m} / \mathrm{s}$ for the same rotational speed and the same air gap.

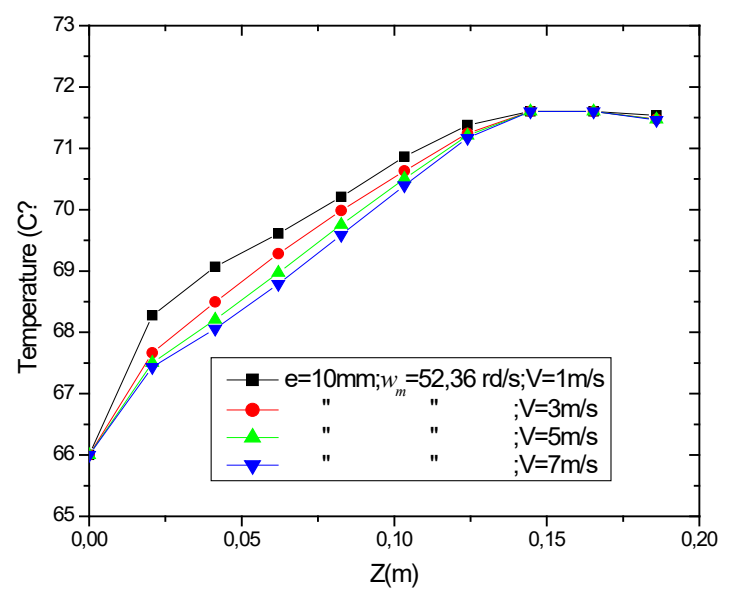

Figure 11. Temperature variation along the groove

It can be seen in Fig. 12 that the Nusselt number increases linearly in the inlet space according to the variation of the axial air injection rate. The coefficient of friction increases in the same way and in the same proportions when air is injected (see Figure 13).

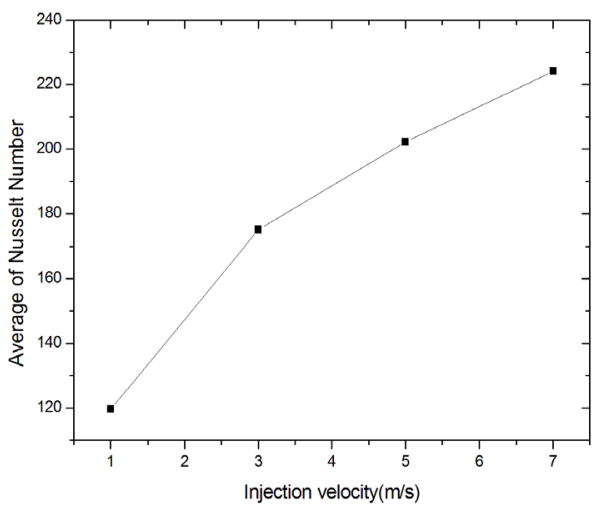

Figure 12. Average Nusselt number

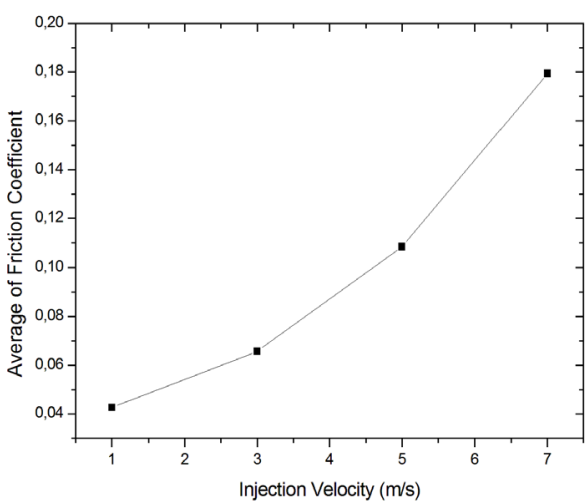

Figure 13. Average friction coefficient
3.3 Impact of the variation of the depth of the groove blade

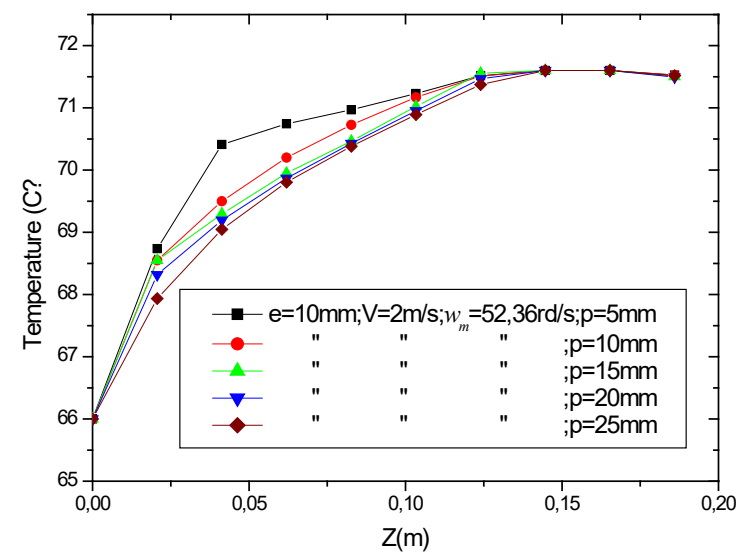

Figure 14. Temperature evolution according to axis $\mathrm{Z}$

For large values of the depth of the groove, convection prevails over the conduction and the little radiation of the surfaces, since there is viscous dissipation of the fluid in the air gap. Fig. 14 shows the evolution of the temperature for different values with the same profile along the rotor. However, the difference is small for the low values of this depth. The figure below shows a temperature gain approaching $2^{\circ} \mathrm{C}$ for a depth $\mathrm{p}=20 \mathrm{~mm}$. It is also noted that the temperature increases with the depth of the groove, but that beyond the value of $15 \mathrm{~mm}$, the temperature profile tends to stabilize. To re-create effects that improve the heat transfer in such a geometrical configuration, the evolution of the depth value must be limited to account for the caused pressure loss effect.

For larger values of this depth (Fig. 15), the greater part of the heat transfer is transmitted by convection. In this case, the latter prevails before the coupling of conduction and radiation in this space, hence the evolution of the Nusselt number. In this case, most of the transfer is done mainly by convection; in addition, the Taylor number is proportional to the square of the rotation speed causing the appearance of a secondary flow.

In fig. 15, the increase in heat transfer through the Nusselt number for the various depth values ranging from depth $p=5$ $\mathrm{mm}$ to $30 \mathrm{~mm}$ is noted. As the depth increases, heat is trapped in the groove, the presence of vortices, allowing Nusselt number to increase.

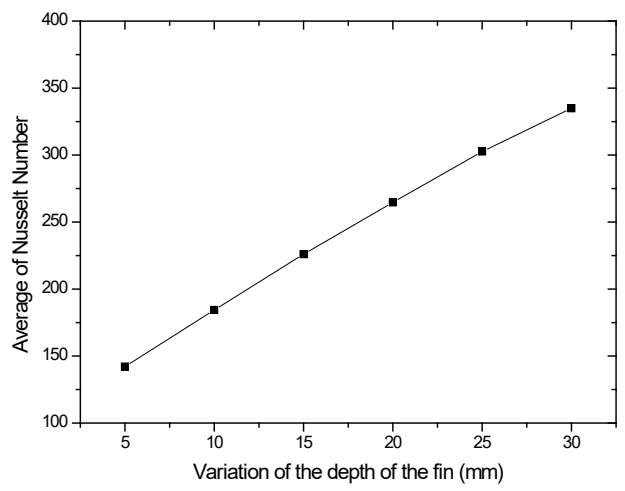

Figure 15. Variation of average Nusselt number for different depths 


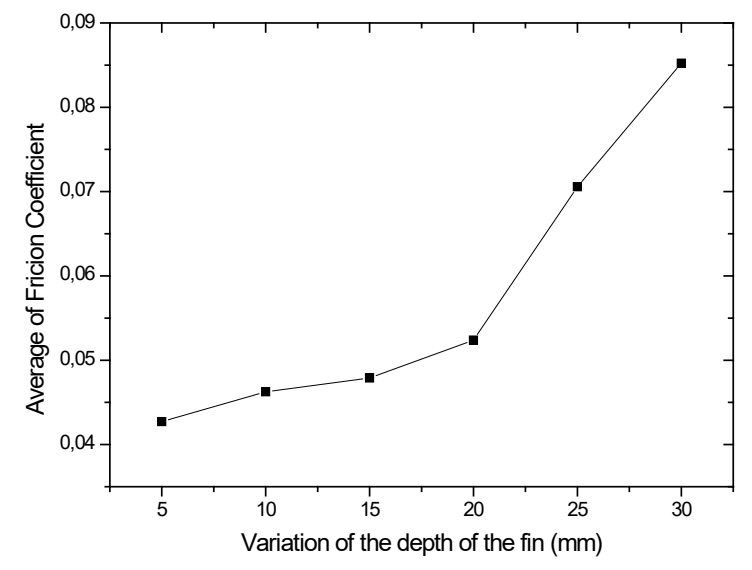

Figure 16. Average friction coefficient variation for different depths

The distributions of the coefficients of friction are represented in fig. 16. It is noted that the profile of the coefficient of friction increases for all values of the depth. It is also observed that this coefficient of friction increases for low flow regimes and decreases for large Reynolds numbers. For the smooth wall, the coefficient of friction remains constant. As the depth increases in value, the turbulence increases thus favoring the presence of a strong depression (fig. 17 below).

The streamlines shown in Figure 18 denote 10 grooves subjected to the effect of rotational speed, injection speed and even air gap. Figure 19 represent the contour of the velocity show the presence of the counter-rotating vortices inside each depth of the rotor blade.
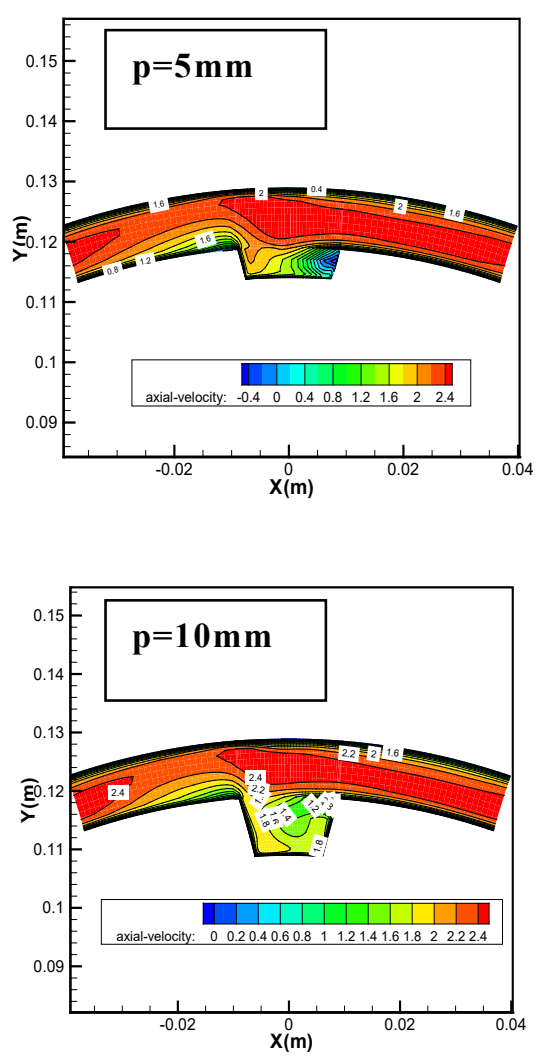
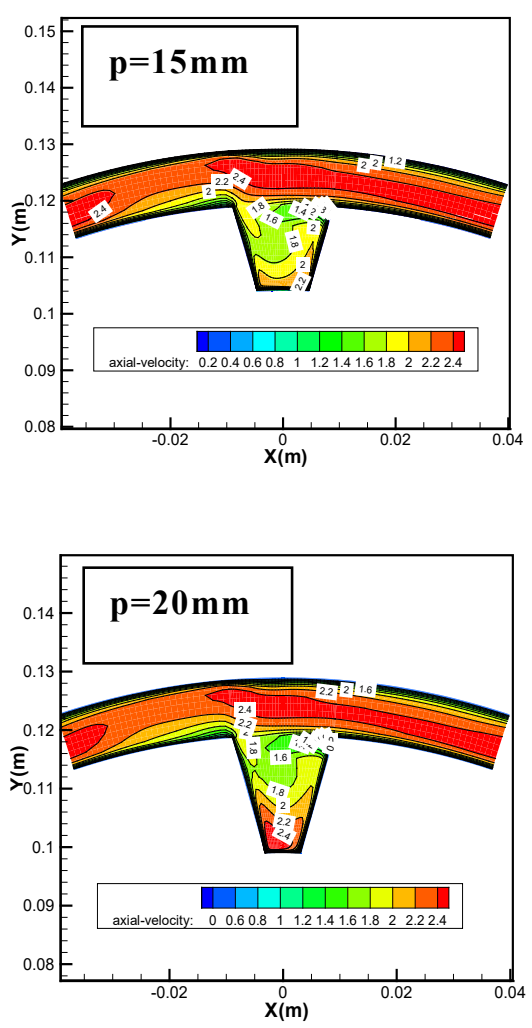

Figure 17. Streamlines for different values of the depth

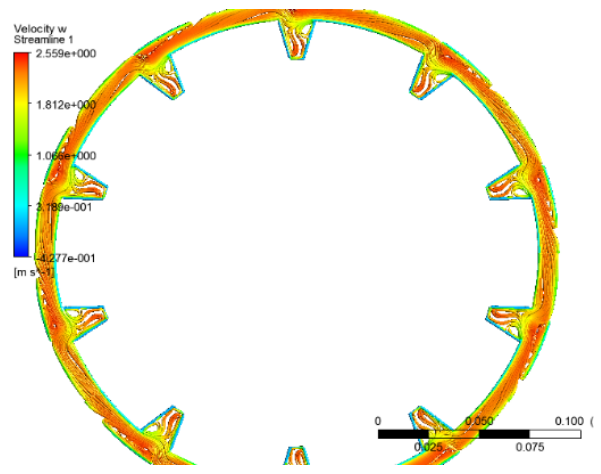

Figure 18. Streamlines for the 10 grooves

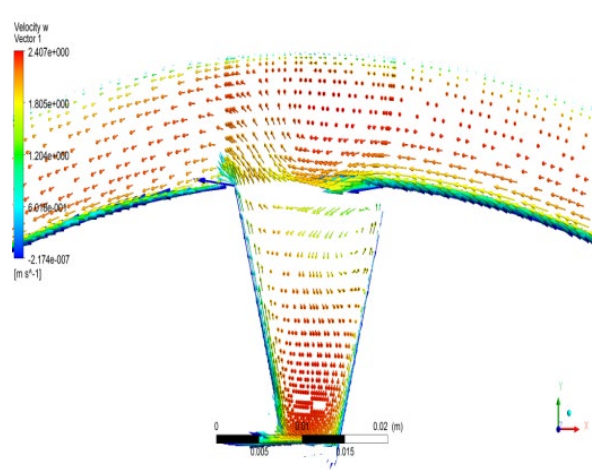

Figure 19. The grooved rotor velocity vector

\subsection{Impact of model variation}

Figure 20 shows the temperature change for the three models used. For the same mesh and under the same numerical conditions, we tested the 3 models namely: The 
Shear Stress Turbulence model"SST", the realizable k- $\varepsilon$ and the Reynolds Stress model "RSM".

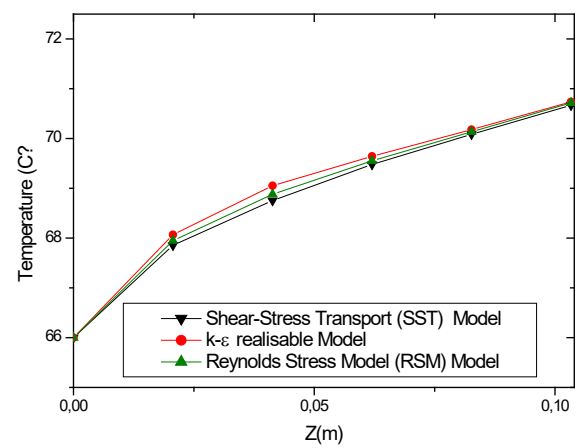

Figure 20. Temperature evolution

\section{CONCLUSION}

The cooling of the rotor-stator utilizing grooves is one of the most widely used methods for improving the thermal performance of an electric motor. In this numerical study, we used the finite volume method in a rotor-stator space with a grooved rotor. The representation of temperature and velocity profiles shows that the selected model SST (Shear Stress Transport) makes it possible to better reproduce this flow. We retained the case of the grooved rotor as opposed to the others (smooth, grooved stator, and grooved rotor-stator). The effect and influence of the depth, the injection speed, the speed of rotation of the air flow and the numerical models tested were observed. From the thermal point of view, this effect resulted in large convective exchanges of the grooved rotor with respect to the other configurations.

In perspective it remains to see the influence of the nature of the cooling fluid, and numerically test other models with other geometries.

\section{REFERENCES}

[1] Taylor GI. (1923). Stability of viscous fluid between two rotating cylinders. Phil. Trans. Roy. Soc, London 223, 289-343.

[2] Gazley C. (1958). Heat-transfer characteristics of the rotational and axial flow between concentric cylinders. Transactions of the ASME 80(1): 79-90.

[3] Becker KM, Kaye J. (1962). Measurements of adiabatic flow in an annulus with an inner rotating cylinder. Journal of Heat Transfer 84(2): 97-105.

[4] Aoki H, Nohira H, Arai H. (1967). Convective heat transfer in an annulus with an inner rotating cylinder. Bulletin of JSME 10(39): 523 . http://dx.doi.org/10.1299/jsme1958.10.523

[5] Tachibana F, Fukui S. (1964). Convective heat transfer of the rotational and axial flow between two concentric cylinders. Bulletin of JSME 7(26): 385. http://dx.doi.org/10.1299/jsme1958.7.385

[6] Ball KS, Farouk B, Dixit VC. (1989). An experimental study of heat transfer in a vertical annulus with a rotating inner cylinder. International Journal of Mass Transfer 32(8): 1517-1527. http://dx.doi.org/10.1016/0017-9310(89)90073-2
[7] Lee YN, Minkowycz WJ. (1989). Heat transfer characteristics of the annulus of two-coaxial cylinders with one cylinder rotating. International Journal of Heat and Mass Transfer 32(4): 711-722.

[8] Pellé J, Harmand S. (2009). Heat transfer study in a rotor stator system air gap with an axial inflow. Applied Thermal Engineering, Elsevier 29(8-9): 1532-1543. http://dx.doi.org/10.1016/j.applthermaleng.2008.07.014

[9] Pellé J, Harmand S. (2007). Heat transfer measurements in an opened rotor-stator system air-gap. Experimental Thermal and Fluid Science 31(3): 165 180.http://dx.doi.org/10.1016/j.expthermflusci.2006.0 .0 18

[10] Andersson H, Lygren M. (2006). LES of open rotorstator flow. International Journal of Heat and Fluid Flow 27(4): 551-557. http://dx.doi.org/10.1016/j.ijheatfluidflow.2006.02.030

[11] Haddadi S, Poncet S. (2008). Turbulence modeling of torsional Couette flows. International Journal of Rotating Machinery 2008: 1-27. http://dx.doi.org/10.1155/2008/635138

[12] Gazley C. (1992). Heat transfer characteristics of rotating and axial flow between concentric cylinders, Trans. ASME. Journal of Heat Transfer 114:589-597.

[13] Gardiner SRM, Sabersky RH. (1978). Heat transfer in an annular gap. International Journal of Heat and Mass $\begin{array}{lll}\text { Transfer } & \text { 21(12): }\end{array}$ http://dx.doi.org/10.1016/0017-9310(78)90002-9

[14] Bouafia M, Bertin Y, Saulnier JB, Ropert P. (1998). Analyse expérimentale des transferts de chaleur en espace annulaire étroit et rainuré avec cylindre intérieur tournant. International Journal of Heat and Mass Transfer 41(10): 1279-1291. http://dx.doi.org/10.1016/S0017-9310(97)00317-7

[15] Peres I, Ziouchi A, Bertin Y. (1994). Caractérisation des échanges de chaleur dans un espace annulaire encoché ou lisse avec le cylindre intérieur tournant. Congrès SFT, 170-177.

[16] Bouafia M, Ziouchi A, Bertin Y, Saulnier JB. (1999). Etude expérimentale et numérique des transferts de chaleur en espace annulaire sans débit axial et avec cylindre intérieur tournant. International Journal of $\begin{array}{lll}\text { Thermal } & \text { Sciences } & 38(7) \text { : }\end{array}$ http://dx.doi.org/10.1016/S0035-3159(99)80035-X

[17] Fénot M, Bertin Y, Dorignac E, Lalizel G (2011). A review of heat transfer between concentric rotating cylinders with or without axial flow. International Journal of Thermal Sciences 50(7): 1138-1155. https://doi.org/10.1016/j.ijthermalsci.2011.02.013

[18] Neti S, Warnock AS, Levy EK, Kannan KS. (1985). Computation of laminar heat transfer in rotating rectangular ducts. Journal of Heat Transfer 107(3): 575582. http://dx.doi.org/10.1115/1.3247463

[19] Levy E, Neti S, Brown G, Bayat F, Kadambi V. (1986). Laminar heat transfer and pressure drop in a rectangular duct rotating about a parallel axis. Journal of Heat Transfer 108(1): 350-356. http://dx.doi.org/10.1115/1.3246928

[20] Soong CY, Yan WM. (1999). Development of secondary flow and convective heat transfer in isothermal/iso-flux rectangular ducts rotating about a parallel axis. International Journal of Heat and Mass Transfer 42(3): 497-510. 
http://dx.doi.org/10.1016/S0017-9310(98)00199-9

[21] Micallef C, Pickering SJ, Simmons K, Bradley K. (2005). Improvements in air flow in the end region of a large totally enclosed fan cooled induction motor. IEEE International Conference on Electric Machines and Drives, pp. 579-584. http://dx.doi.org/10.1109/IEMDC.2005.195781

[22] Jeng TM, Tzeng SC, Lin CH. (2007). Heat transfer enhancement of Taylor-Couette-Poiseuille flow in an annulus by mounting longitudinal ribs on the rotating inner cylinder. International Journal of Heat and Mass Transfer 50(1-2): 381-390. http://dx.doi.org/10.1016/j.ijheatmasstransfer.2006.06.0 05

[23] Romanazzi P, Howey DA. (2015). Air-gap convection in a switched reluctance machine. Tenth International Conference on Ecological Vehicles and Renewable Energies, pp. 1-7.

[24] Poncet S, Haddadi S, Viazzo S. (2010). Numerical modeling of fluid flow and heat transfer in a narrow Taylor-Couette-Poiseuille system. International Journal of Heat and Fluid Flow 32(1): 128-144. http://dx.doi.org/10.1016/j.ijheatfluidflow.2010.08.003

[25] Lancial N, Torriano F, Beaubert F, Harmand S, Rolland G. (2014). Study of a Taylor-Couette-Poiseuille flow in an annular channel with a slotted rotor. International Conference on Electrical Machines, Berlin, pp. 14161423. http://dx.doi.org/10.1109/ICELMACH.2014.6960368

[26] Gilchrist S, Ching CY, Ewing D. (2005). Heat transfer enhancement in axial Taylor-Couette flow. ASME Summer Heat Transfer Conference, San Francisco, USA, pp. 17-22. http://dx.doi.org/10.1115/HT200572746

[27] Fénot M, Dorignac E, Giret A, Lalizel G. (2013). Convective heat transfer in the entry region of an annular channel with slotted rotating inner cylinder. Applied Thermal Engineering 54(1): 345-358. http://dx.doi.org/10.1016/j.applthermaleng.2012.10.039

[28] Lancial N, Torriano F, Beaubert F, Harmand S. (2017). Taylor-Couette-Poiseuille flow and heat transfer in an annular channel with a slotted rotor. International

Journal of Thermal Sciences 112: 92-103. http://dx.doi.org/10.1016/j.ijthermalsci.2016.09.022

[29] Menter FR. (1994). Two-equation eddy-viscosity turbulence models for engineering applications. AIAA Journal 32(8):

1598-1605. http://dx.doi.org/10.2514/3.12149

[30] Wilcox DC. (2006). Turbulence Modeling for CFD. DCW Industries, 3rd edition.

[31] Patankar S, Spalding D. (1972). A calculation procedure for heat, mass and momentum transfer in three dimensional parabolic flows. International Journal of Heat and Mass Transfer 15: 1787-806. http://dx.doi.org/10.1016/0017-9310(72)90054-3

\section{NOMENCLATURE}

$\mathrm{L}$

$\mathrm{R}_{1}$

$\mathrm{R}_{2}$

e

$\mathrm{T}$

$\mathrm{d}_{\mathrm{h}}$

$\mathrm{V}$

$\mathrm{Nu}$

$\mathrm{Cf}$

Ta

$\mathrm{Cp}$

$w_{m}$

\section{Greek symbols}

$\rho$
$\lambda$
$v$
$\varepsilon$
$v t$
$\tau i j$
$\delta_{i j}$
$\phi$
$\omega$

Length of rotor, [m]

Rotor radius, [m]

Stator radius, $[\mathrm{m}]$

width of the magnetized interval, $[\mathrm{m}]$

Temperature, [K]

hydraulic diameter, [mm]

axial speed of fluid, $\left[\mathrm{m} \cdot \mathrm{s}^{-1}\right]$

Nusselt number

Coefficient of friction

Taylor's number

Specific heat at constant pressure, $[\mathrm{J} / \mathrm{Kg} \mathrm{K}]$

Angular velocity, [rad/s]

Fluid density, $\left[\mathrm{kg} / \mathrm{m}^{3}\right]$

Thermal conductivity, $\left[\mathrm{W} \cdot \mathrm{m}^{-1} \cdot \mathrm{K}^{-1}\right]$

Kinematic viscosity, $\left[\mathrm{m}^{2} \cdot \mathrm{s}^{-1}\right]$

Turbulence dissipation rate, $\left[\mathrm{m}^{2} \cdot \mathrm{s}^{-3}\right]$

Turbulent kinematic viscosity, $\left[\mathrm{m}^{2} . \mathrm{s}^{-1}\right]$

Viscous stress tensor

Kronecker delta

Generalized variable

Specific dissipation rate, $\left[\mathrm{s}^{-1}\right]$ 